\title{
Student Perceptions of the Importance of Athletic Teams in Creating Soft Skills: The Case of Rodeo
}

\author{
Ben Walker, Graduate Student \\ Agriculture, Geosciences and Natural Resources, University of Tennessee at Martin \\ Elam Center 1032 Martin, TN 38238, United States \\ Tel: 731-881-7426_E-mail: benbwalk@ut.utm.edu \\ Joey Mehlhorn, Ph.D. (Corresponding Author) \\ Professor of Agribusiness \\ Agriculture, Geosciences and Natural Resources, University of Tennessee at Martin \\ Brehm Hall 254 Martin, TN 38238, United States \\ Tel: 731-881-7275Ｅ-mail: mehlhorn@utm.edu
}

Sandy Mehlhorn, Ph.D., P.E., R.L.S.

Associate Professor of Agricultural Engineering Technology

Agriculture, Geosciences and Natural Resources, University of Tennessee at Martin

Brehm Hall 142 Martin, TN 38238, United States

Tel: 731-881-7263Ｅ-mail: smehlhorn@utm.edu

Rachna Tewari, Ph.D.

Associate Professor of Agribusiness

Agriculture, Geosciences and Natural Resources, University of Tennessee at Martin

Brehm Hall 265 Martin, TN 38238, United States

Tel: 731-881-7196_E-mail: rtewari@utm.edu

Philip Smartt, Ph.D.

Professor of Park Management 
Agriculture, Geosciences and Natural Resources, University of Tennessee at Martin

Brehm Hall 267 Martin, TN 38238, United States

Tel: 731-881-7954Ｅ-mail: psmartt@utm.edu

Received: September 21, 2018 Accepted: October 12, 2018 Published: November 1, 2018

doi:10.5296/ber.v8i4.13678

URL: https://doi.org/10.5296/ber.v8i4.13678

\begin{abstract}
Being a collegiate student athlete is known to be more difficult and hindering on grade point averages then being the typical full-time student. However, it is also thought that being a part of a team can help improve communication skills and thus, assist in receiving a job or simply be more organized in life's day to day activities. This study surveyed alumni and current members of the University of Tennessee at Martin Rodeo Team on their views of how being a student athlete affected their college experience. In this survey, 77 participants were asked questions about the social, academic, and athletic views on being a student athlete at the University of Tennessee at Martin. Another extension to this survey is to show the positive and/or negative effects athletic teams bring a university. This survey questioned athletes on why they chose the university and if they if they perceived being part of the team helped them succeed in future careers. The study gave insight on how student athletes experience college and how universities can help improve the student athlete experience. The study revealed that rodeo had a positive impact on student time management skills and ability to work with others. Results show that a majority of survey participants had a positive and valuable experience being a student athlete at the University of Tennessee at Martin.
\end{abstract}

Keywords: Career Readiness, Scholar Athletes, Soft Skills, Teambuilding

\title{
1. Introduction
}

Collegiate athletics have been prominently portrayed in the media over the years with some positive and negative stories. Many times we see negative stories of NCAA violations by universities and athletes (Rosenberg, 2017). There are also many instances where college athletes are making positive improvements to their communities and schools. Issues on whether athletes should be paid has been a common discussion among critics and athletes alike as college athletics budgets and revenues rise. According to Business Insider, in 2015 the 231 Division I programs reported athletic revenues of $\$ 9.15$ billion with 24 of the programs grossing over $\$ 100$ million in revenue (Gaines, 2016). Research indicates that student athletes do gain positive life experiences from being part of an organized collegiate sport. Benefits such as expanding life experiences, making friends, building character, and developing life skills have all been reported (Chen et. al, 2010; Potuto \& O'Hanlon, 2007). There is also some evidence that successful athletic programs can enhance the overall education experience of all university students (Mixon, et al., 2004). In addition, athletics can 
make a college education possible for those who could not financially afford to get a higher education without the scholarships through athletics. Graduation rates for NCAA athletes has been a point of discussion, but the numbers have been strong with $75 \%$ of college athletes successfully graduating (Sander, 2010).

\section{Review of the Importance of Soft Skills}

Soft skills are among the most sought-after skills by most employers, while being the most difficult to teach. Soft skills is a umbrella term used to describe important skills that are essential for business success and that are of a personal nature (Deepa S. and Seth, 2013). It is important to remember that you should view soft skills in the context of what career you are planning for. Some skills may be viewed as hard skills in one profession, but a soft skill in another (Schulz, 2008). There are many thoughts on exactly what is meant by the term "soft skills". Researchers and business personnel have differing opinions of what constitutes essential soft skills. The common theme is focused on personal qualities such as communication, commitment to a task, team skills, leadership skills, integrity, customer service, and empathy (Perreault, 2004; James and James, 2004; Robles, 2012). It would be expected that students who have proficiency in their field as well as portray a strong grasp of the soft skills are given more priority in employment opportunities, but this is not always the case.

In today's workforce, having technical skills is often not enough to achieve productivity. It also requires soft skills, such as interpersonal and team building skills that help individuals to have good communication skills and become team players. Softs skills have become more critical than ever before as most organizations look to find effective ways to increase productivity and have a competitive advantage (Schulz, 2008). Soft skills are not taught in a vacuum nor are they acquired by teaching. Rather, they are developed through participation and practice. This observation brings us to the aim of this literature review that seeks to discuss soft skills developed that come from being part of a team.

\subsection{Soft Skills Developed From Teamwork}

Effective communication both oral and written has significant influence in getting the desired results from a team. It is an essential element to every team player. Miscommunication can create disharmony and significantly reduce productivity. Thus communication skills are critical for any team work success and failure. Communication skills are necessary for a good working relationship with others. For teamwork to be successful, the relationship among team players must be monitored and maintained. Effective communication skills call for the desire to understand others, satisfy their need and to know their weaknesses, talents and abilities. It involves the concept of understanding of how people work together as a team in fulfilling both individual needs and team objectives. Effective communication means that every member of the team is skilled in listening, problem-solving, and having a good understanding of the impact of the three Vs, which include verbal, vocal, and visual communication (Mulder, 2012). Effective communication skills ensure team players are more confident and enhance the productivity in teamwork. 
In being part of a team, one develops several skills that can be very useful for both communicating with other team members and understanding the information being conveyed. For example, calf roping team members must learn to communicate effectively through practice and spending time together to be successful. They have to be in-sync with each other's verbal and nonverbal cues.

Employers also look for good verbal and non-verbal communication cues such as making good eye contact, confident body posture and asking follow-up questions (Futtrell, 2014). Being able to understand and read non-verbal cues is important for both team success and success in real-world environments.

Some literature suggests that the task complexity and team member diversity in a team are essential elements that influence the development of communication skills and the relationship between team performance and communications skills (Sohmen, 2015; Vanderheyden, Lommelon, \& Cools, 2010). According to Sohmen et al., more complex team tasks are sometimes non-routine and said to require greater cognitive and information processing. Such increase in cognitive demand increases communication which can facilitate potential development and enhancement of communication skills. Additionally, increased cognitive demand in teamwork is more likely to increase creativity and a wider range of thinking processes than most teams produce while going through a complicated task. This enhanced creativity and extended thinking processes facilitate better team communication skills, by helping team members to understand each other effectively. Consequently, the complex tasks involved in teamwork strengthen the need for communication and thus contributes to the development of communication skills. Literature has also suggested that the diversity of a team is likely to contribute to the improvement of additional communication skills and time management skills that are required to perform tasks under diversified work conditions (Vanderheyden, et. al., 2010). These skills are key to developing a leadership mentality.

Contemporary leadership demands for more awareness of the human social interactions and relationships. It requires creating a balance between the hard and the soft leadership skills, leadership, and teamwork. According to Vanderheyden et.al, a leader must be focused on both results and in fostering healthy work relationships (Vanderheyden, et. al., 2010). Though there are many theories on leadership, research suggests that true leadership ability begins with knowing oneself and further emphasizes that self-knowledge is not enough. A good leader must demonstrate undivided attention to the process of self-knowledge and self-development and the building of relationships through the development of others while remaining focused on a clear strategy path that will help achieve a common goal. Leaders must be able to identify the motivation for each team member such as self-interest, exposure, money, and the desire to learn and explore new challenges. A cohesive team is built by an excellent communicator with the required personality to motivate, inspire team members while accommodating the unique desires and needs of each team member.

Collaboration is the lifeblood of being part of any team. It is essential for all teams to learn to work together and collaborate, no matter the size of the team. It involves the act of effectively 
working with others with the aim of achieving a common goal. Collaboration also helps to build trust and respect. These are attained through honesty, openness, consistency, and respect for all team members. These are qualities that are essential in building soft leadership skills. Businesses, just like athletic teams, rely on the effective collaboration of individuals to increase their productivity. In education, instructors teach and develop curriculum in teams. They also work in a team with the administration and other academic employees. The use of instructional teams in education has been shown to be linked with increased student and faculty performance (Ronfeldt, Farmer, McQueen, \& Grissom, 2015). In athletics, team members work together for common goals as well, mainly winning in competition. This type of common purpose to win can lead to stronger bonds among team members. The authors can attest to this fact, as can most readers who have experienced being on a competitive team. Teams can bring diverse people closer together and develop lasting friendships of members. Teams also have advantages in being able to complete tasks. The primary advantage to working in teams is the ability to combine skills and talents effectively across the team. Similar to the concept of specialization of labor, teams can utilize individual strengths to maximize the overall team potential. However, working in a team is not always simple, but individuals can develop and strengthen soft skills over time as a result of being part of a team.

\section{Materials and Methods}

An online survey instrument was developed and deployed using Qualtrics. The survey was approved by the University of Tennessee at Martin Institutional Review Board (17-606-E05/Walk, Ben). An approximately 25 question survey was then created to receive feedback on how participating in college rodeo for the University of Tennessee at Martin affected participants' overall college experience and career paths. Specific survey questions dealt with academic performance, social skills, soft skills, time management, university involvement and career paths.

Each survey asked questions more than once to make sure results were accurate and those taking the survey were giving full attention. All incomplete surveys were not used in the final analysis to minimize errors. In addition, the survey questions were given in a multiple-choice format to reduce error and make data collection accurate. However, at the end of each survey there were a few open-ended questions to allow for more thorough questions and explanations by the participants.

The survey was sent by email to all 44 current members of the University of Tennessee at Martin Rodeo Team. The survey was then administered to University of Tennessee at Martin Rodeo Team alumni via phone call or email receiving 41 responses. These candidates were all informed of the objective of the survey and that it was voluntary. The rodeo alumni list was provided by the UT Martin Rodeo Team and included members from the past 10 years. Survey results were collected and organized into an Excel spreadsheet where data results could be analyzed. The survey response rate for alumni was $100 \%$ and $81.8 \%$ from current team members. Overall the survey received 77 complete responses at a $91.8 \%$ total response rate. Data was summarized into bar charts for ease of discussion. 


\section{MIMacrothink}

\section{Results and Discussion}

Results were mixed when asked if being a member of the team helped them academically while in school. Sixty five percent of alumni and current students stated that being part of the team helped them succeed academically. The authors were surprised by this number and expected a higher percentage of positive responses. Many of the team members shared similar chosen degree paths and coursework. The built in accountability of having teammates in the same class was expected to enhance the overall education experience. Tutors are available and can be scheduled for student athletes at the university, which is very beneficial for those who take advantage of this opportunity. In addition, the GPA requirements to remain eligible for competition would be thought to be an incentive. A possible explanation could be the time requirements of being a student athlete along with travel away from campus for competitions which required missing classes. Athletes many times report that they had to miss classes in order to compete, so it could impact them academically (Ayers, Pazimo-Cervallos, \& Dobose, 2012). Either way it is clear that more emphasis and reinforcement of the tools provided and skills needed to be academically successful should be shared with student athletes.

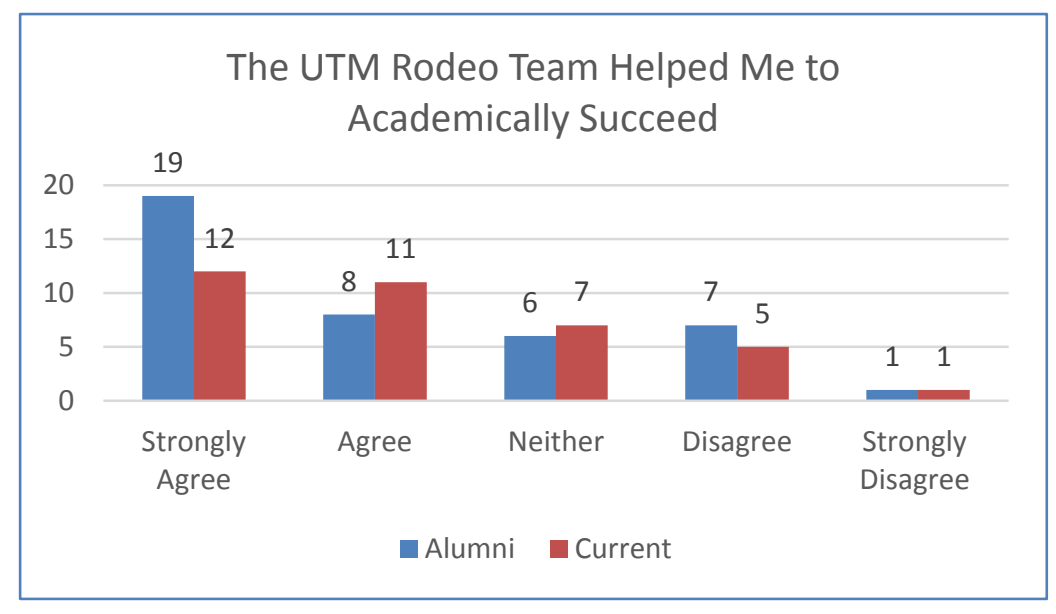

Figure 1. Comparison between current rodeo athletes and alumni on if the UTM rodeo team helped them to academically succeed

Alumni and current athletes were asked about the team's impact on their communication skills. Respondents largely stated that being part of the team improved their individual communication skills, $85 \%$ for alumni and $94 \%$ for current members. This was expected as participants are required to interact with various people such as officials, judges, and media throughout the course of their competitions. Respondents were asked about interpersonal communication within a group setting as well. Figure 2 below shows results for perceptions of group communication skills. Group communication skills refers to interaction between people with a common purpose, such as an athletic team. 


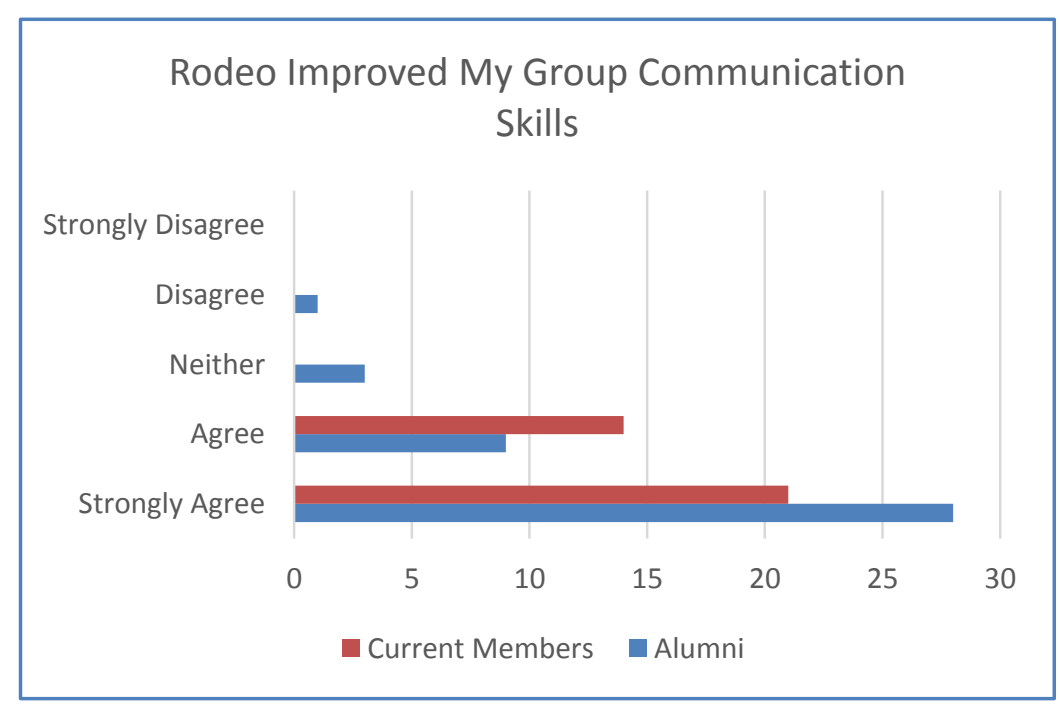

Figure 2. Comparison of alumni and current and more specific opinion of whether being a member of UTM rodeo helped improve communication skills

A majority of participants in the survey agreed that UTM rodeo helped improve their communication skills. On an athletic team such as rodeo, athletes must learn to cooperate and work with people of different ages, sex, and backgrounds every day. This is especially true for team events such as roping. Good communication skills are an important part of developing a successful team. Athletes must also learn to communicate with fans, children, and sponsors at the collegiate level. This skill becomes more important for rodeo athletes who plan to pursue a professional career.

Time management is an important part of any student or professional's career. This is a trait that can be difficult for many college students to master. The time constraints of being a student athlete require them to manage their time efficiently as they balance classes, practice and competition. Student athletes must find time for practice, games/competitions, class, workouts and study time. Being a rodeo athlete also adds the responsibility of taking care of their equine athletes that need to be fed and watered daily. Current student athletes overwhelmingly stated $(91 \%)$ that their time management skills were enhanced from being part of the team. Eighty-eight percent of the alumni agreed that being part of the team improved their time management skills. However, three respondents stated that their time management skills were not improved. One possible explanation is that many rodeo athletes start early in life competing and as a result have already developed the necessary skill to balance athletic competition and school life. This is only backed by anecdotal information from years of working with collegiate rodeo athletes and is not meant to state that participating in collegiate rodeo cannot negatively impact time management skills.

The soft skill of working well with others can also be impacted by participating in organized team activities. The survey found that the majority of respondents stated that being part of the rodeo team helped them in learning to work with other people. This is a valuable skill in today's work environment as a majority of jobs require the ability to work with others. 


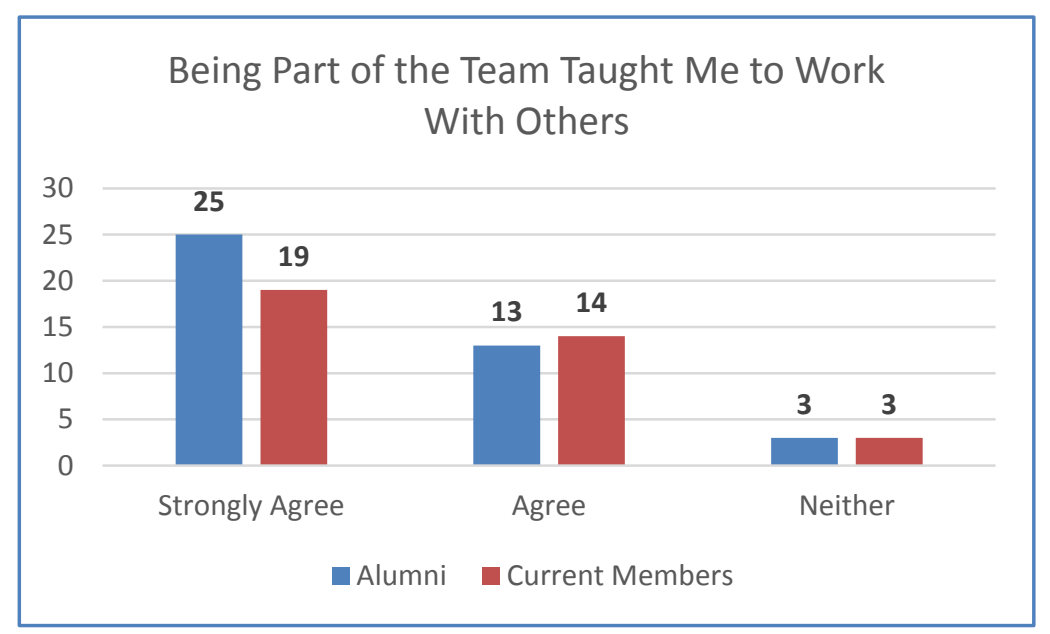

Figure 3. Being Part of the Team Taught Me to Work with Others

The final survey questions sought to understand the importance of academic programs and recruiting rodeo student athletes. Athletic programs work closely with academic programs to ensure that student athletes are prepared for life. Many times this relationship can conflict as the needs of athletic programs (restricted class schedule availability of athletes or eligibility requirements) and a student's degree program can clash. Student athlete schedules are limited due to required practices and travel to compete. It is important that academics and athletics work together to create an environment where student athletes can grow professionally in their chosen career field. Current students and alumni were surveyed about the importance of the academic programs on their decision to attend college. Figure 4 shows the importance of academic programs on college choice for the athletes surveyed. Academic programs were important for some athletes when making a decision to attend. This is a good indicator that college athletics such as rodeo can impact enrollment at the university. It is important to note that some student respondents stated that academic programs did not influence their college choice. For these athletes the decision to attend a particular university was based on athletics. Several Division I student athletes come from other states or even countries to continue engaging in sports at the collegiate level. Without recruitment and athletic teams, some student athletes would have never attended college. Athletic teams, especially successful ones, can be a good way to draw students to the university and increase enrollment. 


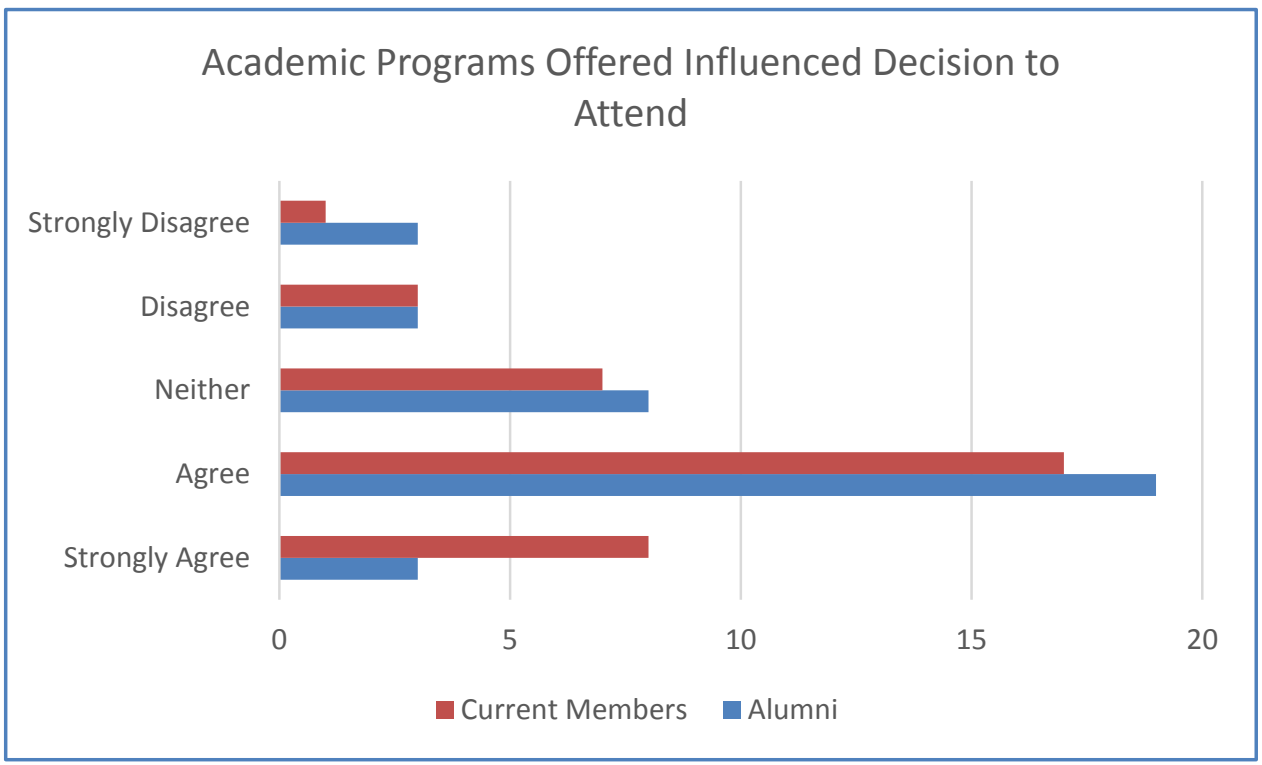

Figure 4. How many alumni and current rodeo athletes chose to attend college because of the academic programs

In the end, all universities and colleges hope to prepare students for their chosen career path. Rodeo team members and alumni were asked if they felt that they were prepared after graduation. While this is a difficult question to quantify, as career readiness can come from many sources that are not connected with the actual educational experience of the university. Rodeo alumni stated that they felt prepared for success after graduation. Eighty five percent agreed or strongly agreed that they were prepared for success. It is expected that the lessons learned through being part of the rodeo team had positive impacts on the student's overall ability to be successful in their career. The soft skills learned from being part of collegiate athletics can complement the overall educational experience of students.

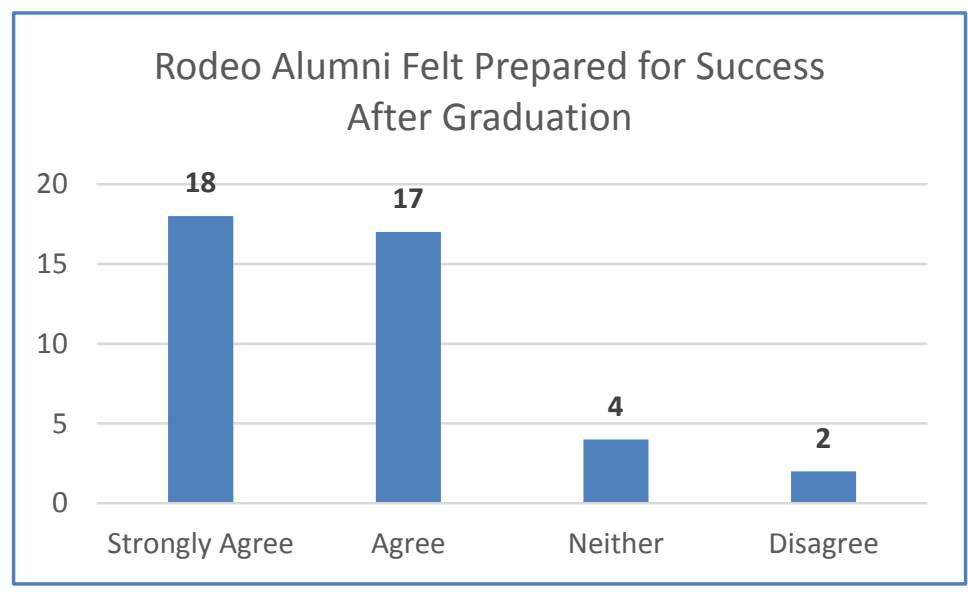

Figure 5. How many student athletes feel as if the education they received from UTM and UTM rodeo will or has given them the tools to succeed in their current or future job

\section{Conclusions and Recommendations}

The results of this study show that being a member of an athletic team is perceived by the 
individual as improving soft skills such as communication, team work, and time management, regardless of their major. Team members also felt that being a part of the team prepared them to succeed academically and in their chosen career.

From the results of the study, it appears the rodeo team is a recruitment tool for the university since respondents overwhelmingly agreed that they chose UTM because of degree programs offered. Further study is recommended of other teams at the university to see if similar perceptions are evident. Other more identifiable traits should also be collected for analysis such as major, GPA, ACT score, etc.

\section{References}

Bernd, S. (2008). The importance of soft skills: Education beyond academic knowledge. NAWA Journal of Language and Communication, 146-154.

Brian, R. (2017, October). How the NCAA Cheats Student Athletes. New York Times. [Online] Available: https://www.nytimes.com/2017/10/03/opinion/how-the-ncaa-cheats-student-athletes.html

Charles, F. (2014). Fundamentals of Selling: Customers for Life Through Service, $13^{\text {th }}$ edition. New York City: McGraw-Hill Higher Education.

Cork, G. (2016). The difference in how much money schools make off of college sports is jarring, and it is the biggest obstacle to paying athletes. Business Insider, [Online] Available: http://www.businessinsider.com/ncaa-schools-college-sports-revenue-2016-10

Deepa, S., \& Seth, M. (2013). Do soft skills matter? - Implications for educators based on recruiters' perspective. The IUP Journal of Soft Skills, VII(1), 7-20.

James, R. F., \& James, M. L. (2004). Teaching career and technical skills in a 'mini' business world. Business Education Forum, 59(2), 39-41.

Karlien, V., Lommelen, B., \& Cools, E. (2010). Cognitive Styles and Teamwork: Examining the Impact of Team Composition on Team Processes and Outcomes. Vlerick Leuven Gent Working Paper Series, January 2010.

Kevin, A., Pazimo-Cervallos, M., \& Dobose, C. (2012). The 20 hours rule: student athletes time commitment to athletics and academics. VAHPERD Journal, 33(1), 22-26.

Marcel, R. (2012). Executive perceptions of the top 10 soft skills needed in today's workplace. Business and Professional Communication Quarterly, 75(4), 453-465. https://doi.org/10.1177/1080569912460400

Matthew, R., Farmer, S. O., McQueen, K., \& Grissom, J. (2015). Teacher collaboration in instructional teams and student achievement. American Educational Research Journal, 52(3), 475-514. https://doi.org/10.3102/0002831215585562

Mixon, Jr, F. G., Trevino, L. J., \& Minto, T. C. (2004). Touchdowns and test scores: exploring the relationship between athletics and academics. Applied Economics Letters, 11(7), 421-424. https://doi.org/10.1080/1350485042000201906 
Mulder, P. (2012). Communication Model by Albert Mehrabian. [Online] Available: https://www.toolshero.com/communication-skills/communication-modle-mehrabian/

Perreault, H. (2004). Business educators can take a leadership role in character education. Business Education Forum, 59(1), 23-24.

Potuto, J. R., \& O'Hanlon, J. (2007). National study of student athletes regarding their experiences as college students. College Student Journal, 41(4), 947-966.

Sander, L. (2010). Graduation Rates for Scholarship Athletes Hold Steady at 79\%, Says NCAA. The Chronicle of Higher Education. [Online] Available: https://www.chronicle.com/article/Graduation-Rates-for/125123

Sohmen, V. S. (2013). Leadership and Teamwork: Two Sides of the Same Coin. Journal of IT and Economic Development, 4(2), 1-18.

Steve, C., Snyder, S., \& Magner, M. (2010). The effects of sports on student-athletes' and non-athletes' social life and identity. Journal of Issues in Intercollegiate Athletics, 3, 176-193.

\section{Copyright Disclaimer}

Copyright for this article is retained by the author(s), with first publication rights granted to the journal.

This is an open-access article distributed under the terms and conditions of the Creative Commons Attribution license (http://creativecommons.org/licenses/by/3.0/). 